ECCOMAS Proceedia
COMPDYN 2021

$8^{\text {th }}$ ECCOMAS Thematic Conference on Computational Methods in Structural Dynamics and Earthquake Engineering M. Papadrakakis, M. Fragiadakis (eds.) Streamed from Athens, Greece, 28 - 30 June 2021

\title{
R/C COLUMN MODELING USING ANSYS AND LOADING RATE AND MESH METHOD INFLUENCE STUDIES
}

\author{
Theodora P. Mitkou ${ }^{1}$, Theodoros A. Chrysanidis ${ }^{1}$ \\ ${ }^{1}$ International Hellenic University \\ P.O. Box 141, P.C. 57400, Sindos, Thessaloniki, Greece \\ cie20140082@cie.teithe.gr, theodoros_gr@yahoo.com
}

\begin{abstract}
Many times, either the research engineer or the design engineer needs to model reinforced concrete $(R / C)$ structural elements in order to study their behavior. In the present research work, an attempt is made to study the correct way of modeling a reinforced concrete column using the finite element ANSYS software. Three-dimensional finite elements are used to model the column. The results of the column modeling and analysis using ANSYS software are compared with the corresponding experimental results of a column with the same geometric characteristics and the same material and load properties as those of the analytical modeling. The only difference between the analytical column modeling and the experimental specimen is the difference in the loading rate. The analytical and experimental results are compared with each other. The influence of the loading rate as well as the mesh method is examined. Useful conclusions are drawn regarding the influence of the loading rate and the mesh method on the behavior and results of reinforced concrete components.
\end{abstract}

Keywords: Column, Reinforced Concrete, Ansys, FEM, Loading Rate, Mesh Methods 


\section{INTRODUCTION}

The rapid growth of technology and the development of the computer, favored the development of theories and computational methods adapted to the capabilities of the computer, in order to solve, yet, unsolved problems in the field of engineering. The most common arithmetic method developed is the Finite Element Method, a numerical approximation method that has the ability to solve complex problems, expressed in the form of differential equations [1]. The basic concept of the Finite Element Method is the ability to represent an area as a set of distinct subareas [2].

As mentioned by Daryl [3], the idea of the Finite Element Method was first presented in the publications of Turner, Clough, Martin and Topp (1956), taking data from research by Courant (1943) [4], Hrenikoff (1941) [5] and McHenry (1943) [6], however, due to the complexity of the arithmetic operations they contained and the lack of computational power of the time, they did not prosper. The official presentation of the Finite Element Method with its current form, took place in the period 1954-60 in the publication of J. Argiris et.al. [7, 8], while the term "Finite Element" was used for the first time in the late 1960s by Clough [9].

In recent years, with the rise of supercomputers and the creation of finite element software run in Windows OS environment, the method has become widely known and accessible, even to the average user, enabling the numerical solution of complex problems while minimizing the need for extensive experimental testing, due to the increased reliability of the method. The most important advantage of the method is that it allows the engineer to see how the product will behave and to point out any mistakes that have been made so far, before proceeding to time-consuming and expensive processes of manufacturing and testing physical prototypes, achieving the early optimization of the product and at the same time, reducing both the time and the cost of studying the experimental process [3].

ANSYS is a general-purpose finite element software, which from the beginning of its creation, has been a pioneering program, with its use in various fields of Engineering [10]. Its analysis process includes the construction of the simplified simulation model, the generation of the finite element grid, the imposition of loads on the model and the solution process using differential equations [10]. The results are exported from the program in a legible way through graphs, tables and / or animations [10].

To investigate the reliability of ANSYS finite element software, the study and comparison of the behavior of a reinforced concrete column, which is subjected to uniaxial compressive load, in relation to the column of the experimental process conducted by Chrysanidis [11]. Chrysanidis in his experiment [11], deals with the study of parameters that affect the stability of seismic reinforced concrete walls, when they are subjected to cyclic loading. For the purposes of the experiment, 10 identical specimens were constructed, on a scale of 1:3, which simulated the edges of a wall, the only difference between the specimens being the increasing degree of elongation and the ratio of longitudinal reinforcement. The fabricated specimens are subjected to two loading cycles, with the first cycle subjecting the specimens to uniaxial tensile loading, with a low loading rate of $4 \mathrm{~mm} / \mathrm{min}$, and then, in the second loading cycle, the specimens being gradually subjected to uniaxial compressive loading with a low loading rate of $1 \mathrm{~mm} / \mathrm{min}$, until their failure. Based on the experimental process, useful conclusions were drawn about the factors that affect the lateral buckling of the specimens. It has to be noted the fact that other experiments have taken place in the international bibliography concerning the behavior of reinforced concrete columns from various researchers [12]-[23].

In the present research work, a comparison is made between the experimental results of the specimen L-0 and the results of the specimens L-0-A and L- $0-B$, which are obtained through simulations using ANSYS software. It must be noted that the specimen L-0 characterized as a 
'virgin specimen' having a degree of elongation equal to $0 \%$ and a longitudinal reinforcement ratio equal to $1.79 \%$. Also, the experimental specimen has the same geometric characteristics, material and load properties as those of the analytical simulation. It is important to note that the experimental specimen was subjected to uniaxial compressive load with a low loading rate of $1 \mathrm{~mm} / \mathrm{min}$. The influence of the soil and its parameters have been neglected [24]-[31].

\section{SIMULATION DESCRIPTION IN ANSYS}

\subsection{Specimens' characteristics}

Therefore, in order to compare the analytical with the experimental results of the L-0 test, as mentioned above, the simulation behavior of two specimens, which are called L-0-A and L-0-B, were studied. The noticeable difference between the two specimens is that the specimen L-0-A, consists only of the active region of the experimental specimen L- 0 . The active area of the specimen L-0 is the area of the specimen between the two steel blades (Figure 1). As a result, the dimensions of the specimen L-0-A were equal to $15 \times 7.5 \times 64 \mathrm{~cm}$. Inside the specimen L-0-A are placed the transverse and longitudinal reinforcement, with the longitudinal reinforcement containing 4 reinforcing bars with a diameter of $8.0 \mathrm{~mm}$ and, at the same time, the transverse reinforcement contained ties with a diameter of $4.2 \mathrm{~mm}$, which are placed with the distance between them being equal to $33 \mathrm{~mm}$.

The specimen L-0-B consists of the integrated specimen L- 0 with dimensions $15 \times 7.5 \times 76$ $\mathrm{cm}$, which at its ends has steel blades. It must be noted that the steel blades penetrate inside of the, so-called, "Shoe". The "Shoe" is solid, in the form of a cube, in which the dimension of each side is equal to $20 \mathrm{~cm}$ and inside of it is placed a spiral with a diameter of $5.0 \mathrm{~mm}$. Specifically, the total height of column of the specimen L-0-B is equal to $90 \mathrm{~cm}$, although, its net height is equal to $76 \mathrm{~cm}$, which is equal to the distance between the two cubes which are called as "Shoes". Inside the specimen L-0-B are placed the transverse and longitudinal reinforcement, with the longitudinal reinforcement containing 4 reinforcing bars with a diameter of $8.0 \mathrm{~mm}$ and, at the same time, the transverse reinforcement contained ties with a diameter of $4.2 \mathrm{~mm}$ which are placed at distances equal to $33 \mathrm{~mm}$.

Figure 1 shows the geometry of the experimental specimen L-0 [11] which forms the base of the simulations of specimens L-0-A and L-0-B. Table 1 shows the specimens' characteristics which are required for the construction of the geometry of the specimens L-0-A and L-0B. The geometry of the steel blades is not contained at Table 1, due to its complexity and as a result is presented in Figure 2. Table 2 shows the material properties for concrete which is used to make the "Shoe" and the column. Also, Table 3 shows the measured material properties for steel which is used for the longitudinal and transverse reinforcement, the spiral reinforcement and the steel blades [11].

\subsubsection{Loading of specimens}

The specimens L-0-A and L-0-B were strained under a uniaxial compressive load applied on the upper "Shoe" of each specimen vertically. The load application took place gradually till the resistance of each specimen reduced and the specimens failed. Despite of the experimental procedure, during which the specimen L-0 was strained at a low monotonic loading rate of $1 \mathrm{~mm} / \mathrm{min}$, at the analytical simulation, the compressive stress of the specimens is carried out at a high loading rate of $1 \mathrm{~mm} / \mathrm{sec}$. Based on that fact, conclusions are drawn, concerning the significant influence of the loading rate on the behavior of reinforced concrete structures. Table 4 shows the load values per time until the resistance of each specimen is greatly reduced and the specimen becomes unstable. 

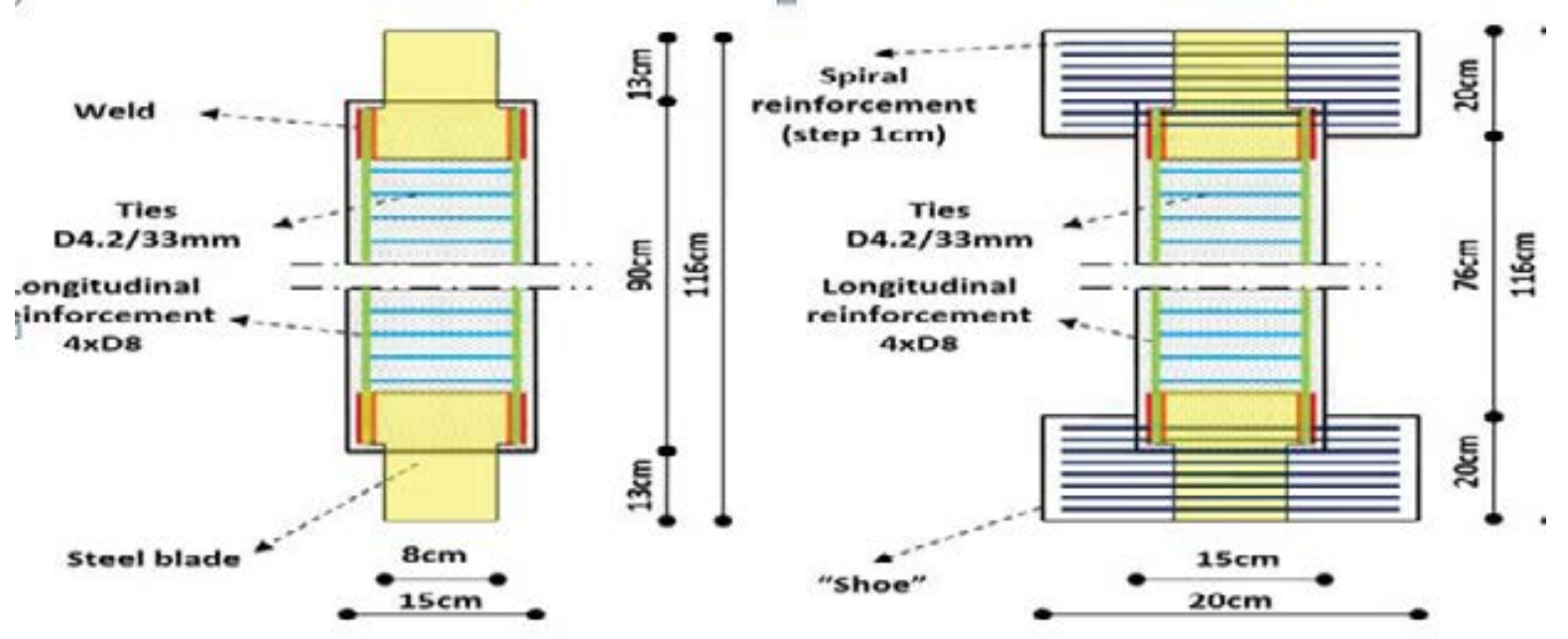

Figure 1: The geometry of the experimental specimen L-0.

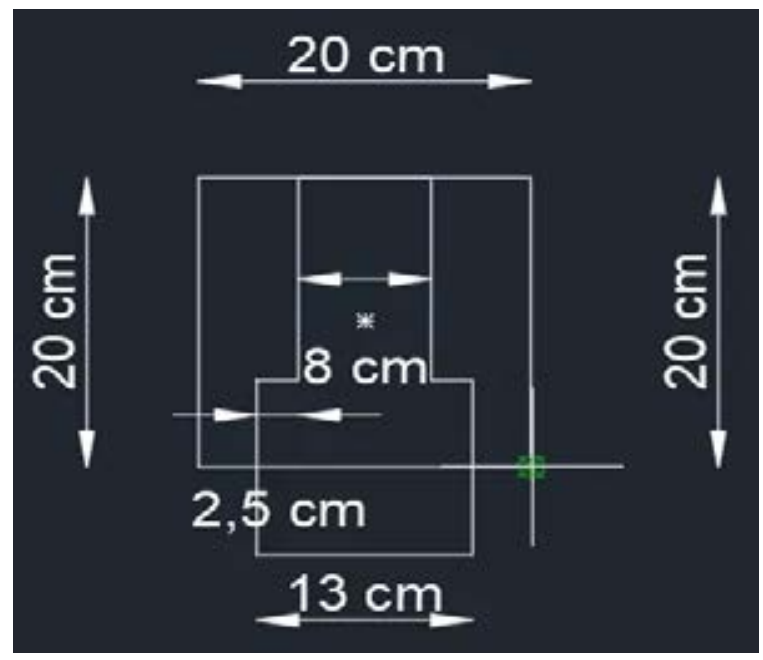

(a)

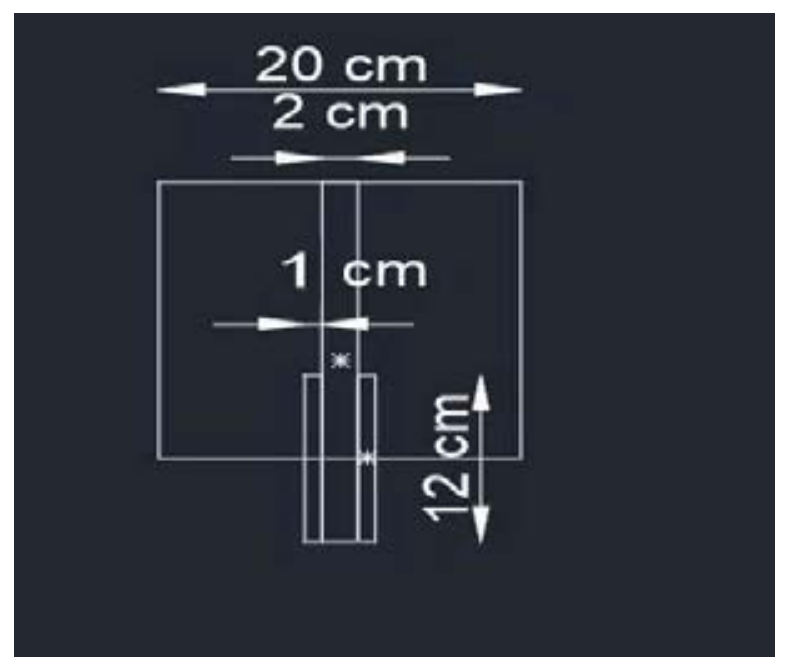

(b)

Figure 2: (a) Face and (b) Side view of steel blade.

\begin{tabular}{|c|c|c|c|c|c|}
\hline SPECIMEN & $\begin{array}{c}\text { COLUMN } \\
(\mathbf{c m})\end{array}$ & $\begin{array}{c}\text { LONGITUDINAL } \\
\text { REINFORCEMENT }\end{array}$ & $\begin{array}{c}\text { TRANSVERSE } \\
\text { REINFORCEMENT }\end{array}$ & $\begin{array}{c}\text { SPIRAL } \\
\text { "SHOE" } \\
(\mathbf{c m})\end{array}$ \\
\hline L-0-A & $15 \times 7.5 \times 64$ & $4 \times \mathrm{D} 8$ & D4.2@33 mm & - & - \\
\hline L-0-B & $15 \times 7.5 \times 76$ & $4 \times \mathrm{D} 8$ & $\mathrm{D} 4.2 @ 33 \mathrm{~mm}$ & $\mathrm{D} 5 / 10 \mathrm{~mm}$ & $20 \times 20 \times 20$ \\
\hline
\end{tabular}

Table 1: Specimens' characteristics. 


\begin{tabular}{|c|c|c|c|c|}
\hline PART & $\begin{array}{c}\text { YOUNG'S } \\
\text { MODULUS }\end{array}$ & $\begin{array}{c}\text { POISSON'S } \\
\text { RATIO }\end{array}$ & $\mathbf{f}_{\text {ck }}$ & DENSITY \\
\hline COLUMN & $29.84 \mathrm{GPa}$ & $v=0.20$ & $23.00 \mathrm{MPa}$ & $2306 \mathrm{kgr} / \mathrm{m}^{3}$ \\
\hline "SHOE" & $30.00 \mathrm{GPa}$ & $v=0.20$ & $54.02 \mathrm{MPa}$ & - \\
\hline
\end{tabular}

Table 2: Concrete mechanical properties.

\begin{tabular}{|c|c|c|c|c|}
\hline MATERIAL & $\begin{array}{c}\text { YOUNG'S } \\
\text { MODULUS }\end{array}$ & $\begin{array}{c}\text { POISSON'S } \\
\text { RATIO }\end{array}$ & $\begin{array}{c}\text { ULTIMATE } \\
\text { STRENGTH }\end{array}$ & YIELD STRESS \\
\hline $\begin{array}{c}\text { LONGITUDINAL } \\
\text { REINFORCEMENT }\end{array}$ & $200 \mathrm{GPa}$ & $v=0.30$ & $743.10 \mathrm{MPa}$ & $603.77 \mathrm{MPa}$ \\
\hline $\begin{array}{c}\text { TRANSVERSE } \\
\text { REINFORCEMENT }\end{array}$ & $200 \mathrm{GPa}$ & $v=0.30$ & $674.01 \mathrm{MPa}$ & $674.01 \mathrm{MPa}$ \\
\hline $\begin{array}{c}\text { SPIRAL } \\
\text { REINFORCEMENT }\end{array}$ & $200 \mathrm{GPa}$ & $v=0.30$ & $749.04 \mathrm{MPa}$ & $742.25 \mathrm{MPa}$ \\
\hline \begin{tabular}{c} 
STEEL BLADE \\
\hline
\end{tabular} & $200 \mathrm{GPa}$ & $v=0.30$ & $582.92 \mathrm{MPa}$ & $404.17 \mathrm{MPa}$ \\
\hline
\end{tabular}

Table 3: Steel mechanical properties.

\begin{tabular}{|c|c|c|c|}
\hline $\begin{array}{c}\text { STEP } \\
(\mathbf{s e c})\end{array}$ & $\begin{array}{c}\text { FORCE } \\
(\mathbf{k N})\end{array}$ & $\begin{array}{c}\text { STEP } \\
(\mathbf{s e c})\end{array}$ & $\begin{array}{c}\text { FORCE } \\
(\mathbf{k N})\end{array}$ \\
\hline $\mathbf{1}$ & 0 & $\mathbf{1 7}$ & 320 \\
\hline $\mathbf{2}$ & 20 & $\mathbf{1 8}$ & 340 \\
\hline $\mathbf{3}$ & 40 & $\mathbf{1 9}$ & 360 \\
\hline $\mathbf{4}$ & 60 & $\mathbf{2 0}$ & 380 \\
\hline $\mathbf{5}$ & 80 & $\mathbf{2 1}$ & 400 \\
\hline $\mathbf{6}$ & 100 & $\mathbf{2 2}$ & 420 \\
\hline $\mathbf{7}$ & 120 & $\mathbf{2 3}$ & 430 \\
\hline $\mathbf{8}$ & 140 & $\mathbf{2 4}$ & 350 \\
\hline $\mathbf{9}$ & 160 & $\mathbf{2 5}$ & 300 \\
\hline $\mathbf{1 0}$ & 180 & $\mathbf{2 6}$ & 250 \\
\hline $\mathbf{1 1}$ & 200 & $\mathbf{2 7}$ & 200 \\
\hline $\mathbf{1 2}$ & 220 & $\mathbf{2 8}$ & 150 \\
\hline $\mathbf{1 3}$ & 240 & $\mathbf{2 9}$ & 100 \\
\hline $\mathbf{1 4}$ & 260 & $\mathbf{3 0}$ & 50 \\
\hline $\mathbf{1 5}$ & 280 & $\mathbf{3 1}$ & 0 \\
\hline $\mathbf{1 6}$ & 300 & & \\
\hline
\end{tabular}

Table 4: Compressive load values per step for analytical simulation. 


\subsection{Simulation of specimens}

\subsubsection{General}

The analytical simulation took place in the educational version of the finite element software ANSYS 20.0. It is important to note that the educational version of ANSYS 20.0 is subject to restrictions. Firstly, the discretization of the specimens requires reducing the numerical number of finite elements until the numerical limit being equal to 32,000, even if the constructed grid is not considered appropriate by the general rules of technical metrics [32]. Furthermore, in the solution stage, the loading time is in seconds versus minutes of the experiment and, as a result, the loading being carried out at a high rate on the specimen. Finally, at the design stage is required to reduce the complexity of the specimen's geometry, which is achieved by making use of the symmetry of the specimen. It is noteworthy that the final restriction took place only during the simulation of the specimen L-0-B.

\subsubsection{Specimen L-0-A}

The specimen L-0-A is simulated via ANSYS 20.0 software and the Workbench subroutine. The first stage of the simulation was the construction of the geometry of the specimen L0 -A which is designed into the software via the SpaceClaim tab. The design process is started from the inside to the outside part of the geometry of the specimen L-0-A. The definition of materials and their properties are defined through the software library. It is noteworthy that the default library values for each of the materials used are modified only when they have been redefined, as shown in Tables 2 and 3, otherwise they remain the same. Figure 3 shows the specimen L-0-A.

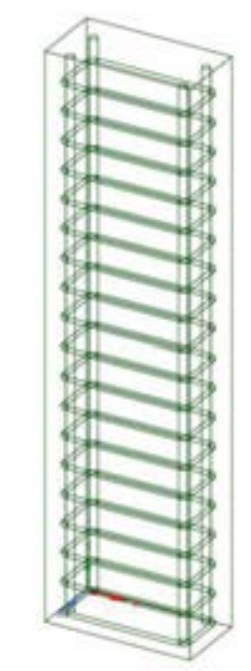

Figure 3: The specimen L-0-A.

The model is discretized via the Multizone Mesh Method by using a set of hexagonal finite elements to construct the grid, with the size of the finite elements being $14 \mathrm{~mm}$. The suitability of the mesh is studied in terms of orthogonal quality, skewness, aspect ratio and element quality parameter, which according to the basic general guidelines for the construction of the mesh [32], the orthogonal quality and skewness parameter provided values within the desired limits even though the aspect ratio parameter did not. In particular, for the skewness parameter, its maximum value is equal to 0.39 , while at the same time, the minimum value of the or- 
thogonal quality parameter is maintained above 0.72 . Nevertheless, the maximum value of the aspect ratio parameter is equal to 4.67 .

Regarding the element quality parameter, all possible mesh methods are investigated for the specimen L-0-A, with the Multizone Mesh Method being preferred, which provided for the element quality parameter a minimum value equal to 0.32 . On the other hand, the mesh, which is made via Automatic mesh method comprises a combination of hexahedral and tetrahedral elements, with the lowest value for the element quality parameter being 0.01 . Moreover, the mesh, which is made via Tetrahedron Mesh Method using a set of tetrahedral elements provides for element quality parameter a minimum value equal to 0.02 . It is recalled that, according to the general guidelines for the constructions of the mesh, the element quality parameter has a value range of $0-1$, with the value 1 being the best [32].

Figure 4 shows the discretion of the specimen L-0-A via Multizone mesh method. Figure 5 shows the element quality parameter for the possible mesh methods. It is noteworthy that the Sweep and Hex Dominant mesh methods could not model the specimen L-0-A. As a result, the software exported the messages shown in Table 5. For simulation of the loads which the specimen L-0-A is subjected to, the categories of Support and Load are used. Therefore, the Fixed Support command is used by the Support category to define that the specimen is connected at the bottom to a rigid body [10]. At the same time, the loading of the specimen is defined using the Force command via the Load category. Thus, the force was applied vertically at the top of the specimen.

The current research work investigates the results of the stress, the deformation and the strain of the specimen L-0-A. It is noteworthy that for the investigation of the deformation is studied either the total deformation of the specimen L-0-A or the deformation to the horizontal and vertical axis.

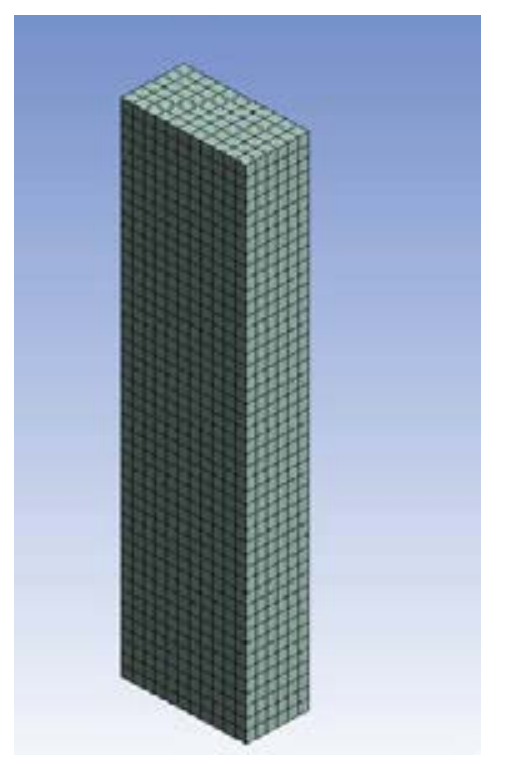

(a)

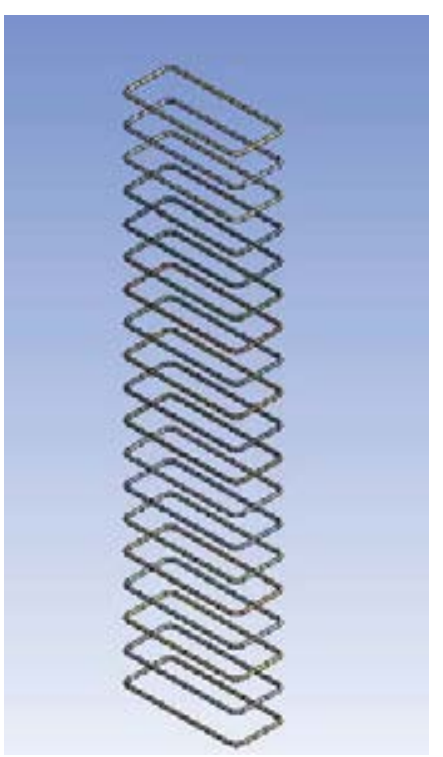

(b)

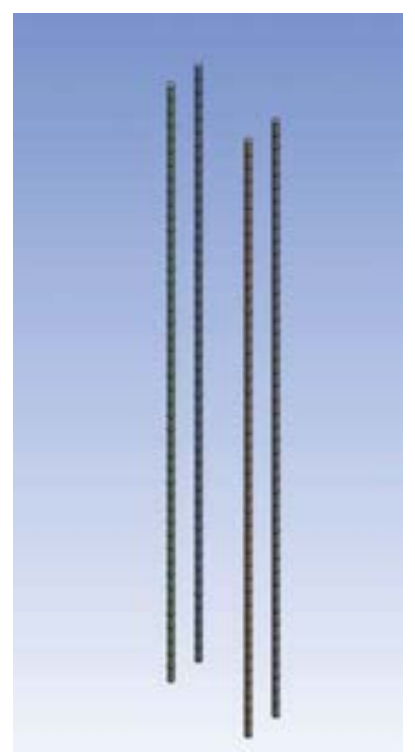

(c)

Figure 4: The mesh of the: (a) Concrete, (b) tie, (c) rebar. 


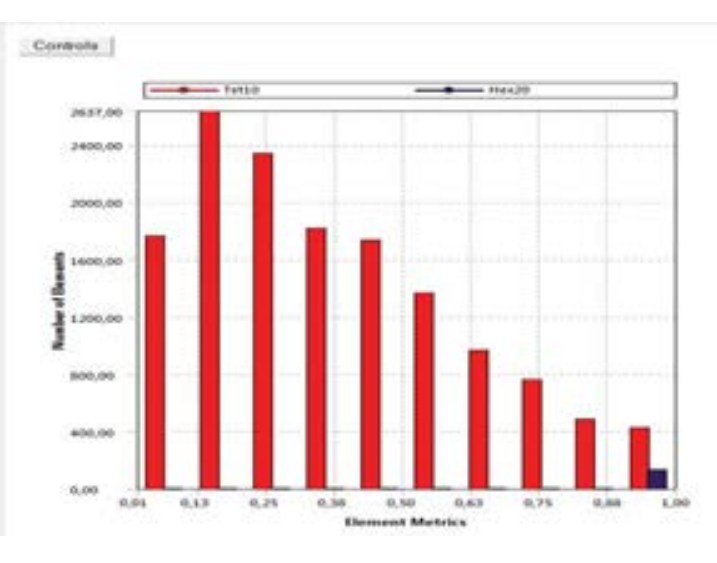

(a)

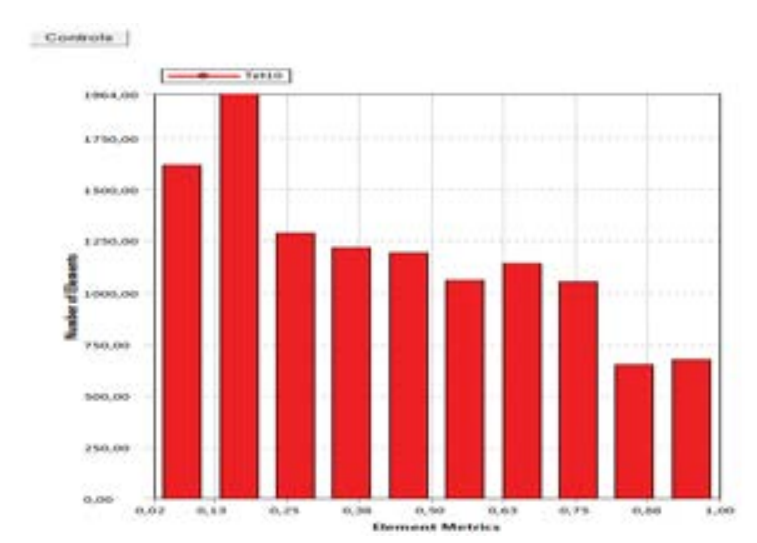

(b)

Controls

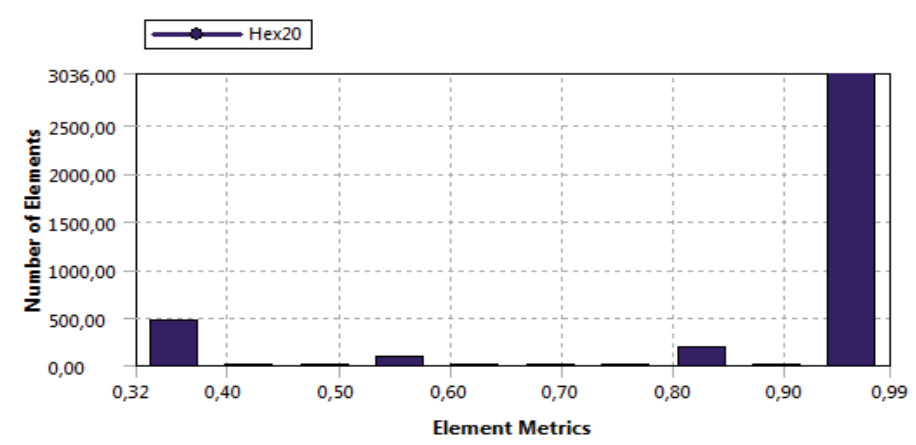

(c)

Figure 5: The element quality parameter for: (a) Automatic, (b) Tetrahedron, (c) Multizone Mesh Method.

\section{Mesh Method Simulation's messages of the specimen L-0-A}

1. Mesher failed to initialize.

2. One or more non-sweepable bodies have sweep method controls

Sweep and cannot be swept.

3. The mesh generation did not complete due to poor quality elements or incorrect input. Please try meshing with another mesh method or different mesh options.

1. Mesher has failed to generate hex dominant mesh for one or more bodies. Try using a different mesh method.

2. A mesh could not be generated using the current meshing options and settings.

3. At least one body selected for hex dominant meshing has a small normalized volume to surface area ratio. The result may be a low percentage of hexs or poorly shaped elements. 


\subsubsection{Specimen L-0-B}

The specimen L-0-B is simulated using ANSYS 20.0 finite element software and the Workbench subroutine. The first stage of modeling was the construction of the geometry of the specimen L-0-A like before, which is designed into the software through four stages via the SpaceClaim tab. The first stage involves the design of the geometry of the column, with the design process being similar to that of the specimen L-0-A, starting from the inside to the outside part of the geometry of the specimen L-0-B.

The second stage is the design process of the geometry of the "Shoe", which is the same design sequence followed as in the first stage, including the design from the inside to the outside part of the geometry of the "Shoe". Specifically, first of all, the geometry of the spiral reinforcement is designed, which is placed inside the "Shoe" and then, the "Shoe" cube that surrounds it. The third design stage includes the creation of the steel blades. As a fourth and final design step, the above steps are assembled to produce the specimen L-0-B.

It is noteworthy that due to the limitations of the educational version of ANSYS, which concern the complexity of the geometry of the specimen L-0-B, it is necessary to use the symmetry of the specimen L-0-B. Otherwise, the ties would probably have to be removed, which would not correspond to the geometric features of the specimen L-0. Figure 6 shows the specimen L-0-B.

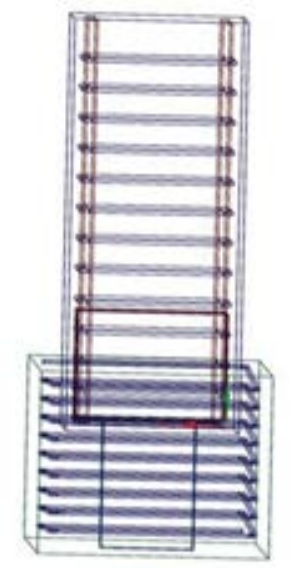

Figure 6: The specimen L-0-B.

The definition of L-0-B test materials and their properties are defined through the software library. It is noteworthy that the default library values for each of the materials used are modified only when redefined, as shown in Tables 2 and 3, otherwise they remain the same. The model is discretized using the Multizone Mesh Method, using a set of hexagonal finite elements to construct the mesh with the finite element size being equal to $18 \mathrm{~mm}$.

The suitability of the mesh is studied in terms of orthogonal quality, skewness, aspect ratio and element quality parameters, which according to the basic general guidelines for the construction of the mesh [32], the orthogonal quality and skewness parameters provided values within the desired limits, even though the aspect ratio parameter did not. In particular, for the skewness parameter, its maximum value is equal to 0.39 , while at the same time, the minimum value of the orthogonal quality parameter is maintained above 0.70 . However, the maximum value of the aspect ratio parameter is equal to 5.60.

As far as the element quality category is concerned, all possible mesh methods for the L-0B specimen are being investigated, with the Multizone method being deemed necessary, as no 
other mesh method was possible due to the complexity of the model geometry and the small numerical limit on the number of finite elements of the mesh. Therefore, for the Multizone Mesh Method, the minimum value in the element quality parameter is 0.17 . It is recalled that, according to the general guidelines for the creation of the grid, the element quality parameter has a value range from $0-1$, with the value 1 indicating the perfect quality [32].

Figure 7 shows the discretion of the specimen L-0-B using Multizone mesh method. Figure 8 shows the element quality parameter for the Multizone mesh method. Table 6 shows the messages exported of the impossible discretization with the other mesh methods. Even if, for the Tetrahedron Mesh Method the software does not output any message, however, the specimen L-0-B could not be discretized according to the constraints, even when the finite element size is equal to $200 \mathrm{~mm}$. For simulation of the forces which the specimen L-0-B is subjected to, the categories of Support and Load are used. Therefore, the Fixed Support command is used by the Support category to define that the specimen is connected at the bottom to a rigid body [10]. At the same time, the loading of the specimen is defined using the Force command via the Load category, thus, the force was applied vertically at the top of the specimen.

The current research work investigates also the results of the stress, the deformation and the strain of the specimen L-0-B. It is noteworthy that for the investigation of the deformation is studied either the total deformation of the specimen L- $0-\mathrm{B}$ or the deformation to the horizontal and vertical axis.

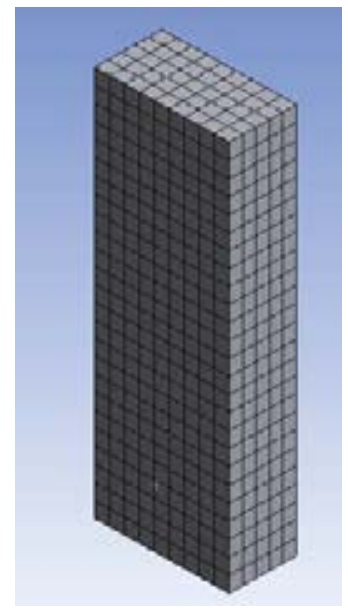

(a)

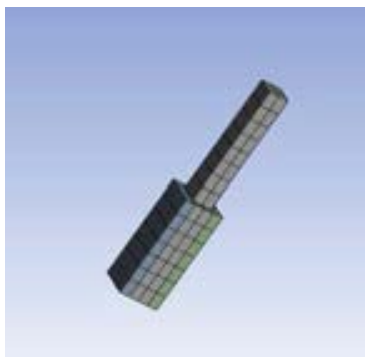

(d)

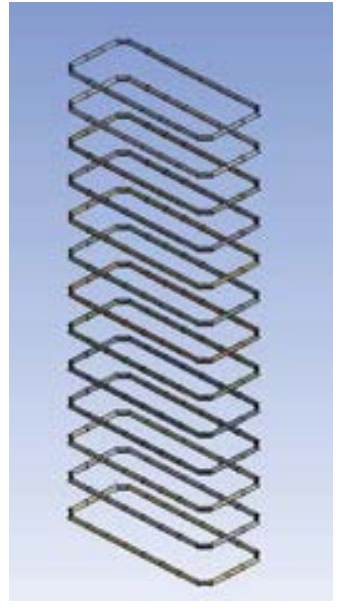

(b)

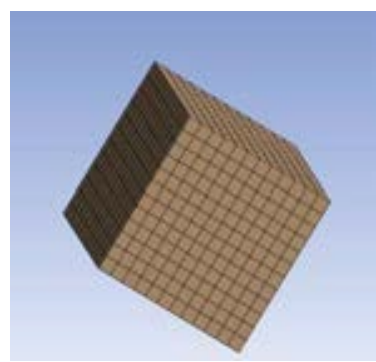

(e)

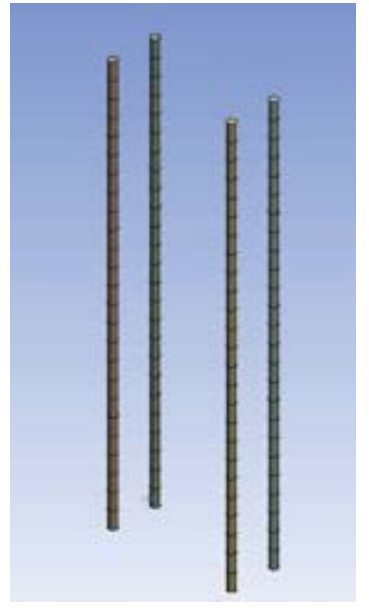

(c)

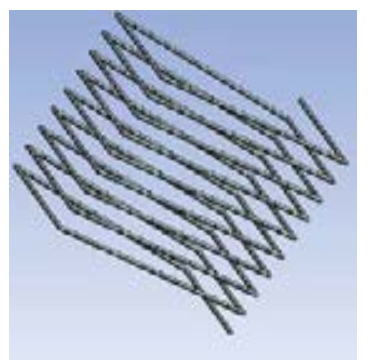

(f)

Figure 7: The mesh of specimen L-0-B: (a) Column, (b) Tie, (c) Rebar, (d) Steel Blade, (e) Stub, (f) Spiral. 


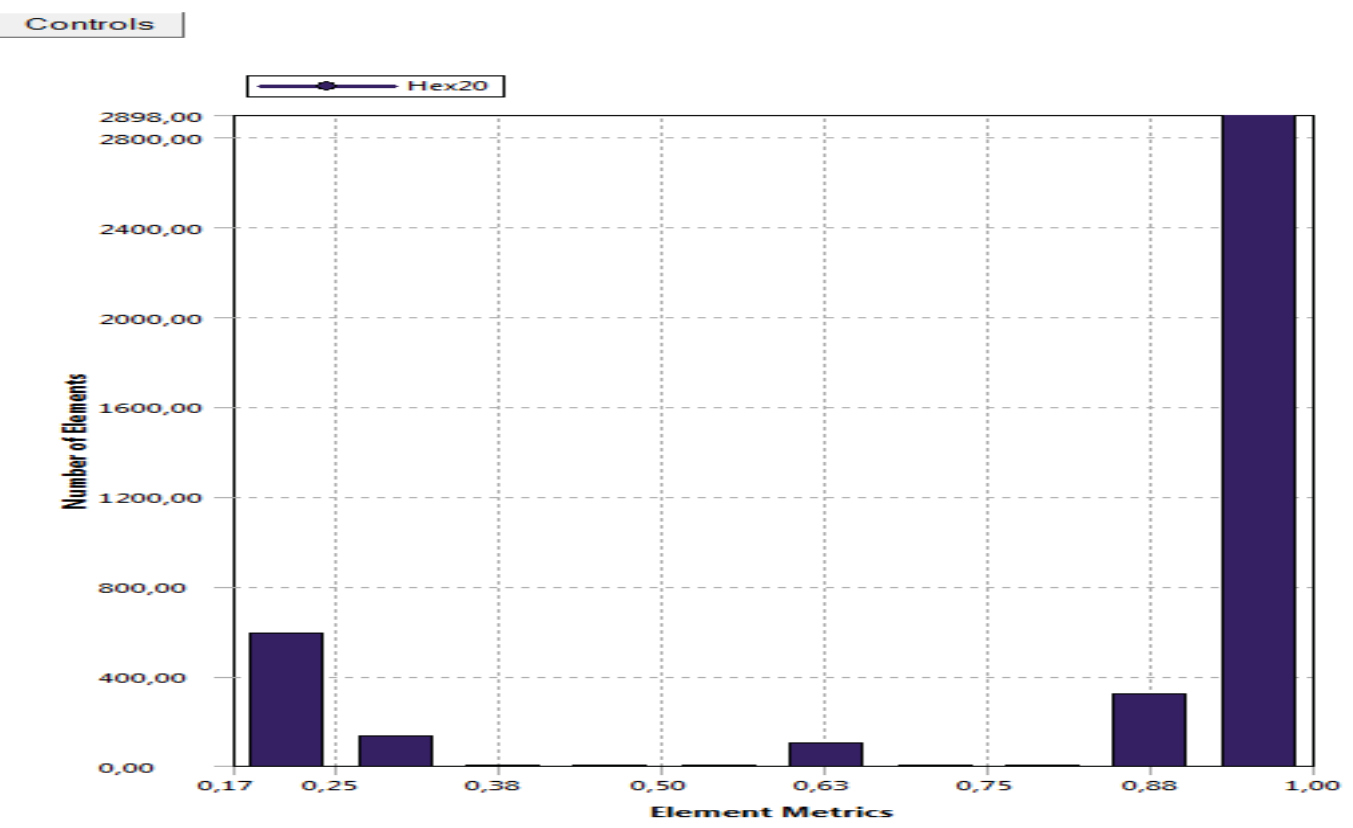

Figure 8: The technical measurement of element quality with the Multizone method for the L-0-B specimen.

Mesh method

Automatic

Sweep

Hex Dominant

\section{Simulation's messages for the specimen L-0-B}

1. The source mesh cannot be correctly copied to the target surface. This might be because the surface is a closed surface with degenerate points. Splitting the surface might help.

1. An error occurred during sweeping meshing a face. Changing element sizing parameters might help.

2. The meshing failed due to quality checks. The mesh does not meet the specified Shape Checking constraints specified. Please look at the mesh quality and adjust meshing options or mesh sizes to obtain a better-quality mesh, or relax the shape check.

3. A mesh could not be generated using the current meshing options and settings.

1. Mesher has failed to generate hex dominant mesh for one or more bodies. Try using a different mesh method.

2. A mesh could not be generated using the current meshing options and settings.

3. At least one body selected for hex dominant meshing has a small normalized volume to surface area ratio. The result may be a low percentage of hexs or poorly shaped elements. 


\section{RESULTS}

\subsection{Analytical results}

Figure 9 shows the Force-Deformation diagrams for the L-0-A, L-0-B and L-0 specimens. The deformation values were the deformation values of the specimens along the vertical axis.

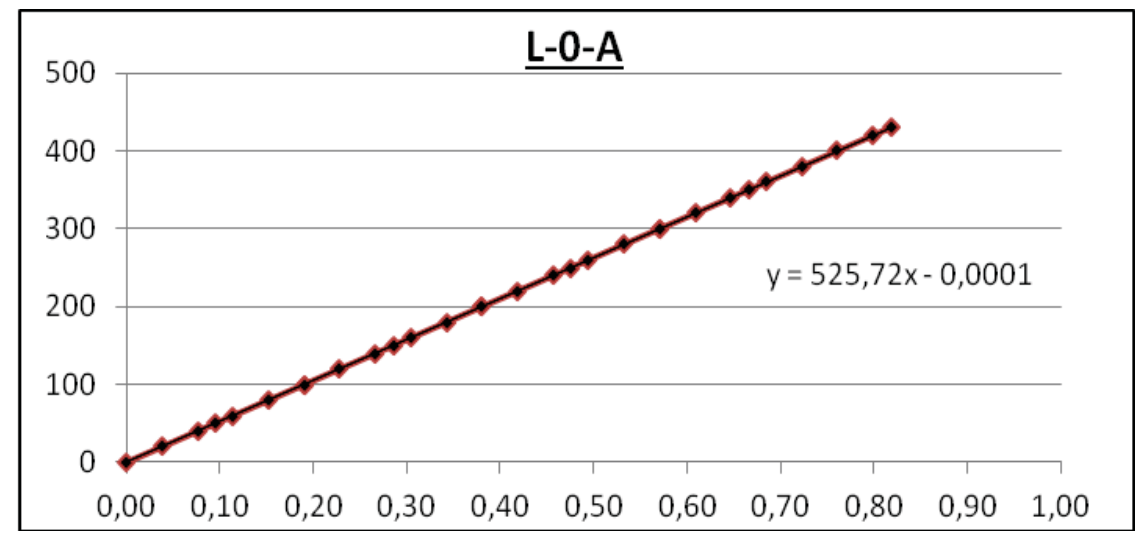

(a)

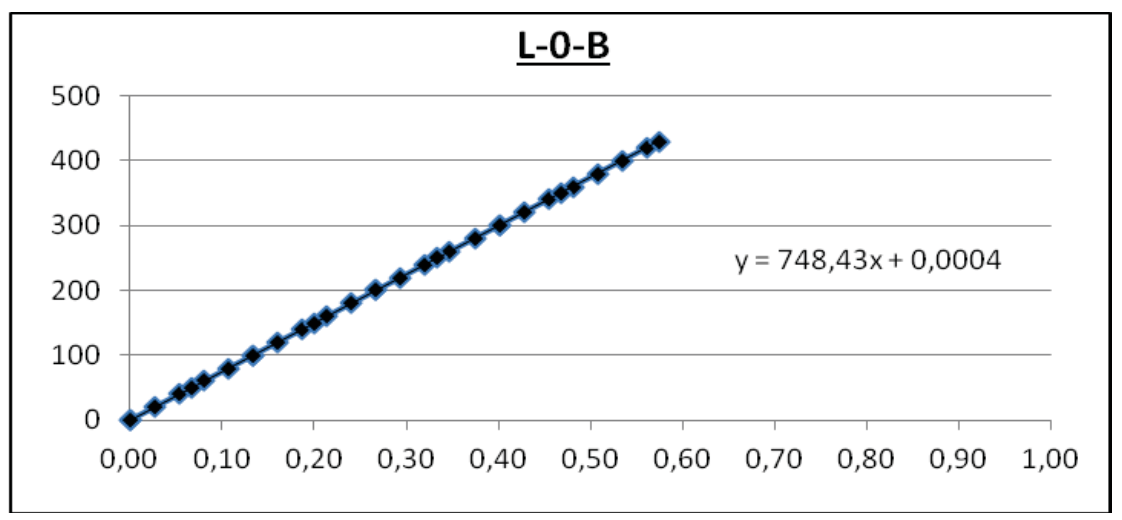

(b)

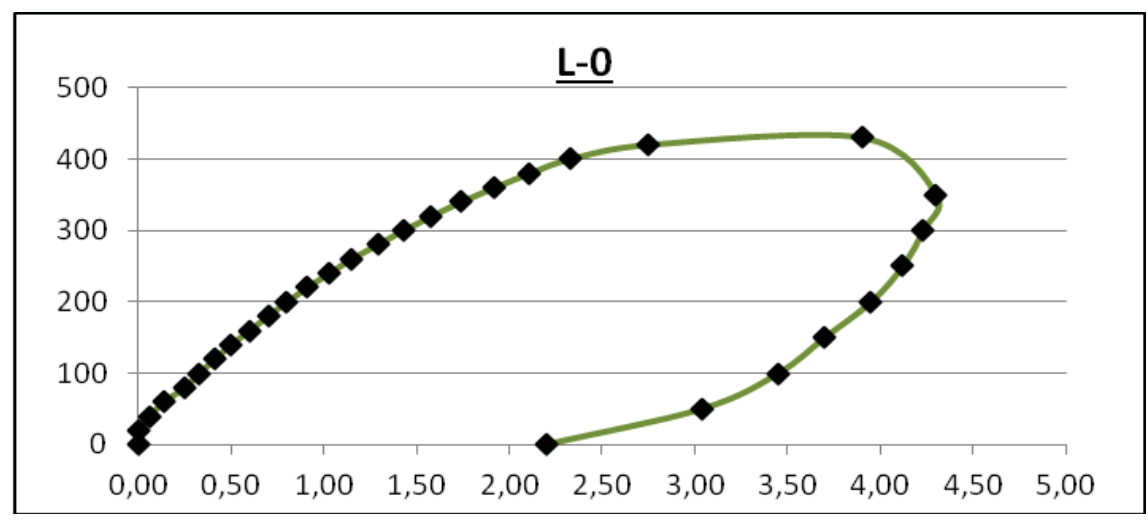

(c)

Figure 9: Load-deformation diagrams for: (a) L-0-A specimen, (b) L-0-B specimen, (c) L-0 specimen. 
Table 7 shows the analytical and experimental deformation results for the specimen L- 0 .

\begin{tabular}{|c|c|c|c|c|c|c|c|c|}
\hline \multirow{2}{*}{$\begin{array}{l}\text { STEP } \\
\text { (sec) }\end{array}$} & \multirow{2}{*}{$\begin{array}{c}\text { FORCE } \\
(\mathbf{k N})\end{array}$} & \multicolumn{3}{|c|}{ L-0-A } & \multicolumn{3}{|c|}{ L-0-B } & \multirow{2}{*}{ L-0 } \\
\hline & & Total & $\mathbf{y}^{\prime} \mathbf{y}$ & $x^{\prime} x$ & Total & $\mathbf{y}^{\prime} \mathbf{y}$ & $\mathbf{x}^{\prime} \mathbf{x}$ & \\
\hline 1 & 0 & 0.00 & 0.00 & 0.00 & 0.00 & 0.00 & 0.00 & 0.00 \\
\hline 2 & 20 & 0.00 & 0.04 & 0.00 & 0.00 & 0.03 & 0.00 & 0.00 \\
\hline 3 & 40 & 0.00 & 0.08 & 0.00 & 0.00 & 0.05 & 0.00 & 0.06 \\
\hline 4 & 60 & 0.00 & 0.11 & 0.00 & 0.00 & 0.08 & 0.00 & 0.14 \\
\hline 5 & 80 & 0.00 & 0.15 & 0.00 & 0.00 & 0.11 & 0.00 & 0.25 \\
\hline 6 & 100 & 0.00 & 0.19 & 0.01 & 0.00 & 0.13 & 0.01 & 0.33 \\
\hline 7 & 120 & 0.00 & 0.23 & 0.01 & 0.00 & 0.16 & 0.01 & 0.41 \\
\hline 8 & 140 & 0.00 & 0.27 & 0.01 & 0.00 & 0.19 & 0.01 & 0.50 \\
\hline 9 & 160 & 0.00 & 0.30 & 0.01 & 0.00 & 0.21 & 0.01 & 0.60 \\
\hline 10 & 180 & 0.00 & 0.34 & 0.01 & 0.00 & 0.24 & 0.01 & 0.70 \\
\hline 11 & 200 & 0.00 & 0.38 & 0.01 & 0.00 & 0.27 & 0.01 & 0.80 \\
\hline 12 & 220 & 0.00 & 0.42 & 0.01 & 0.00 & 0.29 & 0.01 & 0.91 \\
\hline 13 & 240 & 0.00 & 0.46 & 0.01 & 0.00 & 0.32 & 0.01 & 1.03 \\
\hline 14 & 260 & 0.00 & 0.49 & 0.01 & 0.00 & 0.35 & 0.01 & 1.15 \\
\hline 15 & 280 & 0.00 & 0.53 & 0.01 & 0.00 & 0.37 & 0.01 & 1.29 \\
\hline 16 & 300 & 0.00 & 0.57 & 0.01 & 0.00 & 0.40 & 0.01 & 1.43 \\
\hline 17 & 320 & 0.00 & 0.61 & 0.01 & 0.00 & 0.43 & 0.01 & 1.58 \\
\hline 18 & 340 & 0.00 & 0.65 & 0.02 & 0.00 & 0.45 & 0.02 & 1.74 \\
\hline 19 & 360 & 0.00 & 0.68 & 0.02 & 0.00 & 0.48 & 0.02 & 1.92 \\
\hline 20 & 380 & 0.00 & 0.72 & 0.02 & 0.00 & 0.51 & 0.02 & 2.11 \\
\hline 21 & 400 & 0.00 & 0.76 & 0.02 & 0.00 & 0.53 & 0.02 & 2.33 \\
\hline 22 & 420 & 0.00 & 0.80 & 0.02 & 0.00 & 0.56 & 0.02 & 2.75 \\
\hline 23 & 430 & 0.00 & 0.82 & 0.02 & 0.00 & 0.57 & 0.02 & 3.90 \\
\hline 24 & 350 & 0.00 & 0.67 & 0.02 & 0.00 & 0.47 & 0.02 & 4.30 \\
\hline 25 & 300 & 0.00 & 0.57 & 0.01 & 0.00 & 0.40 & 0.01 & 4.23 \\
\hline 26 & 250 & 0.00 & 0.48 & 0.01 & 0.00 & 0.33 & 0.01 & 4.12 \\
\hline 27 & 200 & 0.00 & 0.38 & 0.01 & 0.00 & 0.27 & 0.01 & 3.95 \\
\hline 28 & 150 & 0.00 & 0.29 & 0.01 & 0.00 & 0.20 & 0.01 & 3.70 \\
\hline 29 & 100 & 0.00 & 0.19 & 0.01 & 0.00 & 0.13 & 0.01 & 3.45 \\
\hline 30 & 50 & 0.00 & 0.10 & 0.00 & 0.00 & 0.07 & 0.00 & 3.04 \\
\hline 31 & 0 & 0.00 & 0.00 & 0.00 & 0.00 & 0.00 & 0.00 & 2.20 \\
\hline
\end{tabular}

Table 7: Analytical and experimental deformation results for specimen L-0. 
Table 8 shows the stress results for all three specimens L-0-A, L-0-B and L-0.

\begin{tabular}{|c|c|c|c|c|}
\hline \multirow{2}{*}{$\begin{array}{l}\text { STEP } \\
\text { (sec) }\end{array}$} & \multirow{2}{*}{$\begin{array}{c}\text { FORCE } \\
(\mathbf{k N})\end{array}$} & L-0-A & L-0-B & L-0 \\
\hline & & STRESS (MPa) & STRESS (MPa) & STRESS (MPa) \\
\hline 1 & 0 & 0.00 & 0.00 & 0.00 \\
\hline 2 & 20 & 2.67 & 2.51 & 1.78 \\
\hline 3 & 40 & 5.34 & 5.02 & 3.56 \\
\hline 4 & 60 & 8.01 & 7.53 & 5.33 \\
\hline 5 & 80 & 10.68 & 10.04 & 7.11 \\
\hline 6 & 100 & 13.35 & 12.55 & 8.89 \\
\hline 7 & 120 & 16.02 & 15.06 & 10.67 \\
\hline 8 & 140 & 18.68 & 17.57 & 12.44 \\
\hline 9 & 160 & 21.35 & 20.08 & 14.22 \\
\hline 10 & 180 & 24.02 & 22.58 & 16.00 \\
\hline 11 & 200 & 26.69 & 25.09 & 17.78 \\
\hline 12 & 220 & 29.36 & 27.60 & 19.56 \\
\hline 13 & 240 & 32.03 & 30.11 & 21.33 \\
\hline 14 & 260 & 34.70 & 32.62 & 23.11 \\
\hline 15 & 280 & 37.37 & 35.13 & 24.89 \\
\hline 16 & 300 & 40.04 & 37.64 & 26.67 \\
\hline 17 & 320 & 42.71 & 40.15 & 28.44 \\
\hline 18 & 340 & 45.38 & 42.66 & 30.22 \\
\hline 19 & 360 & 48.05 & 45.17 & 32.00 \\
\hline 20 & 380 & 50.71 & 47.68 & 33.78 \\
\hline 21 & 400 & 53.38 & 50.19 & 35.56 \\
\hline 22 & 420 & 56.05 & 52.70 & 37.33 \\
\hline 23 & 430 & 57.39 & 53.95 & 38.22 \\
\hline 24 & 350 & 46.71 & 43.91 & 31.11 \\
\hline 25 & 300 & 40.04 & 37.64 & 26.67 \\
\hline 26 & 250 & 33.37 & 31.37 & 22.22 \\
\hline 27 & 200 & 26.69 & 25.09 & 17.78 \\
\hline 28 & 150 & 20.02 & 18.82 & 13.33 \\
\hline 29 & 100 & 13.35 & 12.55 & 8.89 \\
\hline 30 & 50 & 6.67 & 6.27 & 4.44 \\
\hline 31 & 0 & 0.00 & 0.00 & 0.00 \\
\hline
\end{tabular}

Table 8: Stress results for specimens L-0. 
Table 9 shows the analytical results of strain for specimens L-0-A and L-0-B compared with the experimental results of strain for specimen L-0.

\begin{tabular}{|c|c|c|c|c|}
\hline \multirow{3}{*}{$\begin{array}{l}\text { STEP } \\
\text { (sec) }\end{array}$} & \multirow{3}{*}{$\begin{array}{c}\text { FORCE } \\
(\mathbf{k N})\end{array}$} & L-0-A & L-0-B & L-0 \\
\hline & & $\begin{array}{l}\text { STRAIN } \\
(\mathrm{mm} / \mathrm{mm})\end{array}$ & $\begin{array}{l}\text { STRAIN } \\
(\mathrm{mm} / \mathrm{mm})\end{array}$ & $\begin{array}{l}\text { STRAIN } \\
(\mathrm{mm} / \mathrm{mm})\end{array}$ \\
\hline & & \%o & $\%$ & $\%$ \\
\hline 1 & 0 & 0.000 & 0.000 & 0.000 \\
\hline 2 & 20 & 0.089 & 0.084 & 0.000 \\
\hline 3 & 40 & 0.179 & 0.168 & 0.067 \\
\hline 4 & 60 & 0.268 & 0.252 & 0.156 \\
\hline 5 & 80 & 0.358 & 0.336 & 0.278 \\
\hline 6 & 100 & 0.447 & 0.420 & 0.367 \\
\hline 7 & 120 & 0.537 & 0.505 & 0.456 \\
\hline 8 & 140 & 0.626 & 0.589 & 0.556 \\
\hline 9 & 160 & 0.716 & 0.673 & 0.667 \\
\hline 10 & 180 & 0.805 & 0.757 & 0.778 \\
\hline 11 & 200 & 0.894 & 0.841 & 0.889 \\
\hline 12 & 220 & 0.984 & 0.925 & 1.011 \\
\hline 13 & 240 & 1.073 & 1.009 & 1.144 \\
\hline 14 & 260 & 1.163 & 1.093 & 1.278 \\
\hline 15 & 280 & 1.252 & 1.177 & 1.433 \\
\hline 16 & 300 & 1.342 & 1.261 & 1.589 \\
\hline 17 & 320 & 1.431 & 1.346 & 1.756 \\
\hline 18 & 340 & 1.521 & 1.430 & 1.933 \\
\hline 19 & 360 & 1.610 & 1.514 & 2.133 \\
\hline 20 & 380 & 1.700 & 1.598 & 2.344 \\
\hline 21 & 400 & 1.789 & 1.682 & 2.589 \\
\hline 22 & 420 & 1.878 & 1.766 & 3.056 \\
\hline 23 & 430 & 1.923 & 1.808 & 4.333 \\
\hline 24 & 350 & 1.565 & 1.472 & 4.778 \\
\hline 25 & 300 & 1.342 & 1.261 & 4.700 \\
\hline 26 & 250 & 1.118 & 1.051 & 4.578 \\
\hline 27 & 200 & 0.894 & 0.841 & 4.389 \\
\hline 28 & 150 & 0.671 & 0.631 & 4.111 \\
\hline 29 & 100 & 0.447 & 0.420 & 3.833 \\
\hline 30 & 50 & 0.224 & 0.210 & 3.378 \\
\hline 31 & 0 & 0.000 & 0.000 & 2.440 \\
\hline
\end{tabular}

Table 9: Strain results for specimens L-0-A, L-0-B and L-0.

\subsection{Analytical results of mesh methods}

For investigation of the influence of mesh methods on the reliability of the analytical results, the specimens L-0-A and L-0-B are discretized using all the available mesh methods of 
the ANSYS software. It is noteworthy that the geometrical characteristics, the properties of the materials and the loading rate remained the same for each simulation, as mentioned earlier. Table 10 shows the stress results according to the mesh method and Table 11 shows the strain results according to the mesh method.

\begin{tabular}{|c|c|c|c|c|c|}
\hline \multirow{3}{*}{$\begin{array}{l}\text { STEP } \\
\text { (sec) }\end{array}$} & \multirow{3}{*}{$\begin{array}{c}\text { FORCE } \\
(\mathbf{k N})\end{array}$} & \multicolumn{3}{|c|}{ L-0-A } & \multirow{3}{*}{$\begin{array}{c}\text { L-0-B } \\
\text { STRESS (MPa) } \\
\text { Multizone }\end{array}$} \\
\hline & & \multicolumn{3}{|c|}{ STRESS (MPa) } & \\
\hline & & Automatic & Tetrahedron & Multizone & \\
\hline 1 & 0 & 0.00 & 0.00 & 0.00 & 0.00 \\
\hline 2 & 20 & 1.99 & 1.90 & 2.67 & 2.52 \\
\hline 3 & 40 & 3.98 & 3.81 & 5.34 & 5.03 \\
\hline 4 & 60 & 5.97 & 5.71 & 8.01 & 7.55 \\
\hline 5 & 80 & 7.96 & 7.62 & 10.68 & 10.07 \\
\hline 6 & 100 & 9.95 & 9.52 & 13.35 & 12.59 \\
\hline 7 & 120 & 11.94 & 11.42 & 16.02 & 15.10 \\
\hline 8 & 140 & 13.93 & 13.33 & 18.68 & 17.62 \\
\hline 9 & 160 & 15.92 & 15.23 & 21.35 & 20.14 \\
\hline 10 & 180 & 17.91 & 17.14 & 24.02 & 22.65 \\
\hline 11 & 200 & 19.90 & 19.04 & 26.69 & 25.17 \\
\hline 12 & 220 & 21.89 & 20.94 & 29.36 & 27.69 \\
\hline 13 & 240 & 23.88 & 22.85 & 32.03 & 30.20 \\
\hline 14 & 260 & 25.87 & 24.75 & 34.70 & 32.72 \\
\hline 15 & 280 & 27.86 & 26.66 & 37.37 & 35.24 \\
\hline 16 & 300 & 29.85 & 28.56 & 40.04 & 37.76 \\
\hline 17 & 320 & 31.84 & 30.46 & 42.71 & 40.27 \\
\hline 18 & 340 & 33.82 & 32.37 & 45.38 & 42.79 \\
\hline 19 & 360 & 35.81 & 34.27 & 48.05 & 45.31 \\
\hline 20 & 380 & 37.80 & 36.18 & 50.71 & 47.82 \\
\hline 21 & 400 & 39.79 & 38.08 & 53.38 & 50.34 \\
\hline 22 & 420 & 41.78 & 39.98 & 56.05 & 52.86 \\
\hline 23 & 430 & 42.78 & 40.94 & 57.39 & 54.12 \\
\hline 24 & 350 & 34.82 & 33.32 & 46.71 & 44.05 \\
\hline 25 & 300 & 29.85 & 28.56 & 40.04 & 37.76 \\
\hline 26 & 250 & 24.87 & 23.80 & 33.37 & 31.46 \\
\hline 27 & 200 & 19.90 & 19.04 & 26.69 & 25.17 \\
\hline 28 & 150 & 14.92 & 14.28 & 20.02 & 18.88 \\
\hline 29 & 100 & 9.95 & 9.52 & 13.35 & 12.59 \\
\hline 30 & 50 & 4.97 & 4.76 & 6.67 & 6.29 \\
\hline 31 & 0 & 0.00 & 0.00 & 0.00 & 0.00 \\
\hline
\end{tabular}

Table 10: Stress results according to the mesh method. 


\begin{tabular}{|c|c|c|c|c|c|}
\hline \multirow{3}{*}{$\begin{array}{c}\text { STEP } \\
\text { (sec) }\end{array}$} & \multirow{3}{*}{$\begin{array}{c}\text { FORCE } \\
(\mathbf{k N})\end{array}$} & \multicolumn{3}{|c|}{ L-0-A } & \multirow{3}{*}{$\begin{array}{c}\text { L-0-B } \\
\begin{array}{c}\text { STRAIN } \\
(\mathrm{mm} / \mathrm{mm}) \%\end{array} \\
\text { Multizone }\end{array}$} \\
\hline & & \multicolumn{3}{|c|}{ STRAIN (mm/mm) \%o } & \\
\hline & & Automatic & Tetrahedron & Multizone & \\
\hline 1 & 0 & 0.00 & 0.00 & 0.00 & 0.00 \\
\hline 2 & 20 & 0.07 & 0.06 & 0.09 & 0.07 \\
\hline 3 & 40 & 0.13 & 0.13 & 0.18 & 0.13 \\
\hline 4 & 60 & 0.20 & 0.19 & 0.27 & 0.20 \\
\hline 5 & 80 & 0.27 & 0.26 & 0.36 & 0.27 \\
\hline 6 & 100 & 0.33 & 0.32 & 0.45 & 0.33 \\
\hline 7 & 120 & 0.40 & 0.38 & 0.54 & 0.40 \\
\hline 8 & 140 & 0.47 & 0.45 & 0.63 & 0.47 \\
\hline 9 & 160 & 0.53 & 0.51 & 0.72 & 0.53 \\
\hline 10 & 180 & 0.60 & 0.57 & 0.81 & 0.60 \\
\hline 11 & 200 & 0.67 & 0.64 & 0.89 & 0.67 \\
\hline 12 & 220 & 0.73 & 0.70 & 0.98 & 0.73 \\
\hline 13 & 240 & 0.80 & 0.77 & 1.07 & 0.80 \\
\hline 14 & 260 & 0.87 & 0.83 & 1.16 & 0.87 \\
\hline 15 & 280 & 0.93 & 0.89 & 1.25 & 0.93 \\
\hline 16 & 300 & 1.00 & 0.96 & 1.34 & 1.00 \\
\hline 17 & 320 & 1.07 & 1.02 & 1.43 & 1.07 \\
\hline 18 & 340 & 1.13 & 1.08 & 1.52 & 1.13 \\
\hline 19 & 360 & 1.20 & 1.15 & 1.61 & 1.20 \\
\hline 20 & 380 & 1.27 & 1.21 & 1.70 & 1.27 \\
\hline 21 & 400 & 1.33 & 1.28 & 1.79 & 1.33 \\
\hline 22 & 420 & 1.40 & 1.34 & 1.88 & 1.40 \\
\hline 23 & 430 & 1.43 & 1.37 & 1.92 & 1.43 \\
\hline 24 & 350 & 1.17 & 1.12 & 1.57 & 1.17 \\
\hline 25 & 300 & 1.00 & 0.96 & 1.34 & 1.00 \\
\hline 26 & 250 & 0.83 & 0.80 & 1.12 & 0.83 \\
\hline 27 & 200 & 0.67 & 0.64 & 0.89 & 0.67 \\
\hline 28 & 150 & 0.50 & 0.48 & 0.67 & 0.50 \\
\hline 29 & 100 & 0.33 & 0.32 & 0.45 & 0.33 \\
\hline 30 & 50 & 0.17 & 0.16 & 0.22 & 0.17 \\
\hline 31 & 0 & 0.00 & 0.00 & 0.00 & 0.00 \\
\hline
\end{tabular}

Table 11: Strain results according to the mesh method.

\section{ANALYTICAL INVESTIGATION}

\subsection{Investigation of analytical results}

Therefore, the analytical research of the two simulations in the present research has led to the following common results to between the two simulations:

- The rate of loading, in the case of reinforced concrete structures, affects the deformation results, by increasing the resistance of the specimen. 
- The rate of loading of vertical and horizontal deformation remains completely constant throughout the load, which is not observed in the experimental results.

- The rate of loading of stress remains perfectly constant throughout the loading duration, just as in the experimental results.

- The values of the transverse deformation remain below zero throughout the loading duration, without observing the behavior of the two stages of deformation, which are described in the research of Chrysanidis [11].

- Increase of the resistance of the specimen L-0-A and L-0-B in relation to the resistance of the experimental specimen L-0.

- The average value of the percentage error for the simulation of specimen L-0-A is of the order of $395.2 \%$, while for the simulation of specimen L-0-B is of the order of $598.8 \%$.

With the percentage error values far from the permissible limits, it becomes obvious that neither the analytical results of the specimen L-0-A nor of the specimen L-0-B converge with the experimental results of Chrysanidis [11] and as a result the two simulations cannot be characterized as reliable in terms of the coherence of the results.

\subsection{Investigation of mesh method's results}

Based on the element quality diagrams and the tables of the mesh method results, it appears that:

\section{A. For the simulation of specimen L-0-A}

- The rate of loading, in the case of reinforced concrete structures, affects the deformation results, increasing the strength of the specimen.

- The mesh is performed only by Automatic, Tetrahedron and the Multizone mesh methods, due to the geometry of the simulation which contained bodies that Sweep and Hex Dominant mesh methods could not mesh.

- Due to the limitation of the educational version for the number of finite elements used, the mesh of the Automatic, Tetrahedron and Multizone mesh methods do not meet the requirements of a suitable grid, according to the general rules for the element quality measurement technique. However, from the above methods, the Multizone mesh method is preferred.

- A mesh made only of hexahedron finite elements provides more reliable results than a mesh made of tetrahedron finite elements.

- The type and the number of finite elements do not affect the behavior of the specimen during the loading period.

\section{B. For the simulation of specimen L-0-B}

- The mesh is generated using only the Multizone mesh method.

- Due to the complexity of the geometry, the method of the Automatic and Patch Confirming Tet, cannot distinguish the model with a number of finite elements less than 32,000 . 
- The Sweep method and the Hex Dominant method do not produce a mesh, due to the geometry of the specimen containing bodies, in which the methods cannot work.

- Due to the limitation of the educational version for the number of finite elements used, the mesh of the Multizone method does not meet the requirements of a suitable grid, according to the general rules for the technique of measurement of the element quality category. However, the choice of mesh made with the Multizone mesh method is considered necessary.

- The type and the number of finite elements do not affect the behavior of the specimen during the loading period.

\section{INFLUENCE OF LOADING RATE}

According to the detailed results, there are two stages during the duration of the loading. The first stage includes the time from the imposition of the load at $0 \mathrm{kN}$ to the loading with a load equal to $430 \mathrm{kN}$. Then, the second stage includes the unloading process of the model. In particular, in the first stage there is an increase in the deformation and stress at a constant rate, until the stress reaches its maximum value, in contrast to the experimental results where the rate of deformation follows a different flow. Then, in the second stage, the deformation and the stress are reduced at a constant rate until the values are 0 , returning the specimen to its original state. It is noteworthy that during the experimental procedure, there is a deformation with the higher value being calculated at $10 \%$ of the height of the L- 0 specimen, measured by its base. In addition, it is observed that the number and type of finite elements do not affect the behavior of the specimen during the loading process, despite of the mesh method used.

Therefore, it turns out that the universal load in the behavior of the specimen L-0-A and L0 -B in relation to the experiment by Chrysanidis [11], is due solely to the high loading rate of the two simulations, with which concludes that, in reinforced concrete structures, the loading rate affects the results of deformation increasing the strength of the structure.

\section{INFLUENCE OF MESH METHOD}

The type and number of finite elements used greatly influence the reliability of the results. In particular, the influence of the type of finite elements on the suitability of the mesh and consequently on the reliability of the results is observed. More specifically, a grid made of hexadecimal elements, such as the mesh of Multizone mesh method, is more suitable, according to the general technical metrics rules, and at the same time more reliable than a grid made of tetrahedral elements, such as the mesh of Tetrahedron mesh method. On the other hand, the number of finite elements depends on the complexity of the geometry of the model that it is called upon to mesh. A grid with a small number of elements in a complex geometry, is quite difficult to be characterized as suitable and at the same time, its results cannot be considered as being reliable.

The large numerical differences between the simulation results are due to both the chosen mesh method and the size of the finite elements of the grid. However, it is impossible to create a more appropriate grid than that in section 2, due to the limitations of the ANSYS educational version.

\section{CONCLUSIONS}

By comparing the analytical results of the L-0-A and L-0-B specimens with the experimental results of the L-0 specimen [7], the reliability of the ANSYS software and the factors 
which might influence it are investigated. The resulting conclusions can be summarized as follows:

- The rate of loading, in the case of reinforced concrete structures, affects the deformation results, increasing the strength of the specimen.

- The number and the size of the finite elements of a simulation affect the accuracy and reliability of the results.

- The number and type of finite elements do not affect the behavior of the model during loading period.

- The number and type of finite elements of a simulation affect the accuracy and reliability of the results, whether or not the grid is suitable.

- The number of finite elements depends on the complexity of the model geometry.

- The type of finite elements affects the reliability of the simulation results, with hexahedron elements providing more accurate results.

\section{REFERENCES}

[1] Bathe, K. J., 2006, Finite Element Procedures, Watertown: Prentice Hall, Pearson Education, Inc.

[2] Madenci, E., Guven, I., 2015, The Finite Element Method and Applications in Engineering Using ANSYS, New York: Springer.

[3] Daryl, L. L., 2007, A First Course in the Finite Element Method, Toronto, Ontario: Thomson Canada Limited.

[4] Courant, R., 1943, "Variational Methods for the Solution of Problems of Equilibrium and Vibrations", Bulletin of the American Mathematical Society, Vol. 49, pp. 1-23.

[5] Hrennikoff, A., 1941, "Solution of Problems in Elasticity by the Frame Work Method", Journal of Applied Mechanics, Vol. 8, No. 4, pp. 169-175.

[6] McHenry, D., 1943, "A Lattice Analogy for the Solution of Plane Stress Problems", Journal of Institution of Civil Engineers, Vol. 21, pp. 59-82.

[7] Argyris, J. H., 1954-1955, "Energy Theorems and Structural Analysis", Aircraft Engineering.

[8] Argyris, J. H., and Kelsey, S., 1960, Energy Theorems and Structural Analysis, Butterworths, London, (collection of papers published in Aircraft Engineering in 1954 and 1955).

[9] Clough, R. W., 1960, “The Finite Element Method in Plane Stress Analysis”, Proceedings, American Society of Civil Engineers, 2nd Conference on Electronic Computation, Pittsburgh, PA, pp. 345-378.

[10] Lee, H. H., 2010, Finite Element Simulations with Ansys Workbench 12, Taiwan: Schoff Development Corporation

[11] Chrysanidis, T., 2019, "Influence of elongation degree on transverse buckling of confinedboundary regions of R/C seismic walls", Construction and Building Materials, pp.703-720. 
[12] Y. Chai and D. Elayer, "Lateral stability of reinforced concrete columns under axial reversed cyclic tension and compression," ACI Structural Journal, vol. 96, no. 5, pp. 780-789, 1999.

[13] P. Smaś, "Design of clamped columns for maximizing the axial displacement at buckling," Structural and Multidisciplinary Optimization, vol. 33, no. 3, pp. 229-241, 2007, doi: 10.1007/s00158-006-0056-4.

[14] T. Chrysanidis, "Influence of elongation degree on transverse buckling of confined boundary regions of R/C seismic walls," Construction and Building Materials, vol. 211, pp. 703-720, Jun. 2019, doi: 10.1016/J.CONBUILDMAT.2019.03.271.

[15] T. Chrysanidis, "Low Reinforced Shear Walls: Displacements and Failure Modes Due to Lateral Buckling," International Journal of Science and Engineering Investigations, vol. 5, no. 55, pp. 143-148, 2016.

[16] M. Moyer and M. Kowalsky, "Influence of tension strain on buckling of reinforcement in concrete columns," ACI Structural Journal, vol. 100, no. 1, pp. 75-85, 2003.

[17] H. S. Essa, "Stability of Columns in Unbraced Frames," Journal of Structural Engineering, vol. 123, no. 7, pp. 952-957, 2002, doi: 10.1061/(asce)07339445(1997)123:7(952).

[18] J. Aristizabal-Ochoa, "Stability of columns under uniform axial load with semirigid connections," Journal of Structural Engineering, vol. 120, no. 11, pp. 3212-3222, 1994.

[19] T. Chrysanidis and I. Tegos, "Size of seismic tensile strain and its influence on the displacements due to transverse buckling of ultra-highly reinforced structural walls," ARPN Journal of Engineering and Applied Sciences, vol. 11, no. 23, pp. 13884-13890, 2016.

[20] T. Chrysanidis, "Size of seismic tensile strain and its influence on the lateral buckling of highly reinforced concrete walls," IOSR Journal of Mechanical and Civil Engineering, vol. 11, no. 1, pp. 18-22, 2014, doi: 10.9790/1684-11121822.

[21] T. Chrysanidis, "Evaluation of Out-of-Plane Response of R/C Structural Wall Boundary Edges Detailed with Maximum Code-Prescribed Longitudinal Reinforcement Ratio," International Journal of Concrete Structures and Materials, vol. 14, no. 1. 2020, doi: 10.1186/s40069-019-0378-4.

[22] T. Chrysanidis and I. Tegos, "Influence of elongation degree on out-of-plane buckling of R/C structural walls with a medium high reinforcement ratio," International Journal of Civil Engineering and Technology, vol. 7, no. 4, pp. 358-364, 2016.

[23] T. Chrysanidis and I. Tegos, "Out-of-plane buckling of highly reinforced seismic walls: Displacements and mode of failure," International Journal of Civil Engineering and Technology, vol. 5, no. 6, pp. 101-107, 2014.

[24] N. Alamanis, "Uncertainties and optimization in geotechnical engineering," American Scientific Research Journal for Engineering, Technology, and Sciences, vol. 38, no. 1, pp. 92-111, 2017.

[25] N. Alamanis and P. Dakoulas, "Effect of the spatial variability of soil properties on the seismic vulnerability of slopes with embedded oil and natural gas pipelines," in 6th 
International Conference on "Energy, Sustainability and Climate Change" (ESCC 2019), 2019.

[26] N. Alamanis and P. Dakoulas, "Simulation of random soil properties by the Local Average Subdivision method and engineering applications," Energy Systems, pp. 1-21, 2019, doi: 10.1007/s12667-019-00362-y.

[27] N. Alamanis and P. Dakoulas, "Effect of spatial variability of soil properties on the stability and permanent seismic displacements of highway slopes," in The 17th European Conference on Soil Mechanics and Geotechnical Engineering, 2019.

[28] G. Papageorgiou, N. Alamanis, I. Chouliaras, and P. Kapsali, "Decision making for designing infrastructure projects: The case of the city of Larissa, Greece," Journal of Engineering and Architecture, vol. 7, no. 1, pp. 115-125, 2019, doi: 10.15640/jea.v7n1a13.

[29] N. Alamanis, G. Papageorgiou, P. Chantzopoulou, and I. Chouliaras, "Investigation on the influence of permeability coefficient $\mathrm{k}$ of the soil mass on construction settlements. Cases of infrastructure settlements in Greece," Wseas Transactions on Environment and Development, vol. 15, pp. 95-105, 2019.

[30] A. Mouratidis and G. Papageorgiou, "A Rational Approach for Optimization of Road Upgrading," Canadian Journal of Civil Engineering, vol. 37, no. 11, pp. 1462-1470, 2010 .

[31] G. Papageorgiou, N. Alamanis, and N. Xafoulis, "Methodology for optimization of road works schedule according to local climatic data," International Journal of Recent Technology and Engineering, vol. 8, no. 4, pp. 1470-1476, 2019.

[32] ANSYS, Inc, 2010, Ansys Meshing User's Guide, Canonsburg: ANSYS Inc. 